\title{
OBESIDADE: UMA TENTATIVA DE ABORDAGEM NA EDUCAÇÃO FÍSICA ESCOLAR DE 5a À 8a SÉRIES
}

\author{
OBESITY: AN ATTEMPT TO APPROACH IN PHYSICAL \\ EDUCATION AT SCHOOL FROM 5TH TO 8TH GRADES
}

\author{
Lara Novais Cremonesi ${ }^{1}$ \\ Antonia Dalla Pria Bankoff ${ }^{2}$ \\ Carlos Aparecido Zamai ${ }^{3}$
}

\section{RESUMO}

O objetivo deste trabalho foi estudar como a Educação Física Escolar tem tratado o tema obesidade. Dentre as escolas escolhidas num primeiro momento, foram selecionadas duas: uma estadual, de nível socioeconômico médio-baixo, e

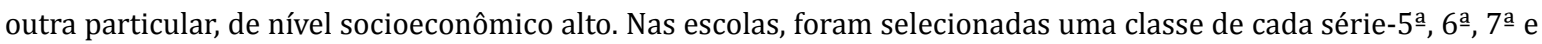
8 ${ }^{\mathrm{a}}$. Foram desenvolvidos dois protocolos: um voltado para os alunos de 5 ${ }^{\mathbf{a}}$ à $8^{\mathrm{a}}$ séries do Ensino Fundamental, outro para os professores de Educação Física Escolar. Resultados: Em relação a freqüência em ambas as escolas a educação física é oferecida uma vez por semana, sendo aula dupla; quanto ao nível de participação há alunos que participam ativamente, outros parcialmente, há alunos que sentem-se excluídos, sentem-se discriminados; quanto a abordagem nas aulas de educação física sobre temas de saúde, a escola estadual se mostrou mais efetiva; quanto ao professor enfatizar a importância das atividades físicas a escola estadual se mostrou mais eficaz. Quanto aos professores, o professor da escola estadual mostrou-se mais atento a esta temática através de seu planejamento. Conclusão: Os alunos da escola estadual e o professor mostraram estarem mais envolvidos com as questões sobre obesidade e outros temas relacionados com a saúde.

Palavras Chaves: Educação Física escolar. Obesidade. Escolares. Saúde.

\section{ABSTRACT}

The aim of this work was to study how the Physical Education has treated the topic of obesity. Among the schools chosen at first, we selected two: one State, level medium-low, and one particular of high socioeconomic status. In schools, we selected a class of each series -5 th, 6 th, 7 th and 8 th. The choice of schools was made randomly from the permission thereof. We developed two protocols: one facing the students of 5th to 8th grades of elementary school, the other for teachers of Physical Education. Results: Regarding the frequency at both schools physical education is offered once a week, with double lesson, the level of participation for students who actively participate, others partially, there are students who feel excluded, they feel discriminated, as the approach in physical education classes on topics of health, the state school was more effective, as the teacher to emphasize the importance of physical activity to a state school is more effective. For teachers, the school teacher state was more attentive to this issue through your planning. Conclusion: Students in the public school and the teacher showed they were more concerned with issues of obesity and other health-related topics.

Key Words: Physical Education. Obesity. School. Health

Fecha de recepción: 15 de julio de 2014

Fecha de aprobación: 12 de noviembre de 2014

1 E.E. Barão Geraldo de Rezende-Campinas-Brasil.

2 Universidade Federal de Mato Grosso do Sul-Campus de Três Lagoas-MS-Brasil. Correo electrónico: dallabankoff@bol.com.br

3 Universidade Estadual de Campinas- Brasil. 
Para citar este artículo:

Novais, L., Pria, A., Aparecido, C. (2014). Obesidade: uma tentativa de abordagem na educação física escolar de $5^{\mathrm{a}}$ à $8^{\underline{a}}$

séries. Revista Lúdica Pedagógica, (20), 119-128.

\section{INTRODUÇÃO}

Definir obesidade é na maioria das vezes, uma tarefa difícil, pois existem situações em que se olha para um indivíduo e diz-se, na sua ótica, que ele é obeso. Entretanto, existem casos em que tal afirmativa é extremamente duvidosa. Também, anunciado por Bankoff, et al. (2002), Guedes \& Guedes (1997, p. 187) e Bankoff (2012 p. 11), em casos como este, torna-se necessário realizar exames mais sofisticados, como a bio-impedanciometria, densidade corporal ou então, avaliações físicas para definir melhor a porcentagem de tecido adiposo ou então o Índice de Massa Corporal-IMC.

De acordo com o padrão de beleza aceito por nossa sociedade, ditado principalmente pelos meios de comunicação, são bonitas aquelas pessoas altas e magras. Estética à parte, o maior problema é que a obesidade aumenta o risco para uma série de doenças, como por exemplo, as articulares, distúrbios lipídicos, hipertensão arterial, diabetes, que, por sua vez, aumentam os riscos de mortalidade por doenças cardiovasculares, principalmente. Mas, o que faz com que algumas pessoas se tornem obesas? Certamente existe uma interação de fatores: genéticos, metabólicos, psicológicos e culturais (Bankoff, 2012). Atualmente existe um grande número de estudos que mostram que o excesso de peso e gordura corporal está relacionado a doenças crônico-degenerativas, e assim reduzem significativamente a qualidade de vida dos indivíduos (Mello, Luft \& Meyer, 2004).

Pollock e Wilmore (1993) descrevem que o excesso de peso, "é definido como aquela condição onde o peso do indivíduo excede ao da média da população, determinada segundo o sexo, a altura e o tipo de compleição física" (p.47), sendo a obesidade caracterizada como um excesso de gordura corporal, mais comum em mulheres do que em homens.

Das patologias nutricionais a obesidade é que mais tem apresentado aumento em seus números, não apenas nos países ricos, mas também nos países em desenvolvimento. Todo um sistema de vida inadequado provavelmente favorece este tipo de acontecimento: sedentarismo, hábitos familiares inadequados, alimentação insatisfatória, excesso de carboidratos na dieta, a velocidade da refeição, os lanches desequilibrados e o consumo de doces e guloseimas (Bankoff, 2012, Rinaldi, et al. 2008).
Uma pesquisa nacional realizada pelo Ministério da Saúde em 2012, por telefone-VIGITEL, em saúde escolar sobre obesidade e sobre peso mostrou que o sobrepeso atinge $34,8 \%$ dos meninos e $32 \%$ das meninas na faixa etária de 5 a 9 anos. Já a obesidade foi constatada entre $16,6 \%$ dos meninos e entre $11,8 \%$ das meninas na mesma faixa etária. Entre as crianças a partir de 10 anos e jovens de até 19 anos, sobrepeso atinge $21,7 \%$ do total dos meninos e a obesidade, 5,9\%. Entre as meninas nessa faixa etária, 15,4\% mostraram estar com sobrepeso e 4,2\%, obesidade. Quanto à percepção da imagem corporal, $17,7 \%$ do sexo masculino disseram estar gordos ou muito gordos. Os escolares do sexo feminino observaram-se desta forma em 21,3\% dos casos (Ministério da Saúde, 2012).

A Organização Mundial da Saúde informou que o número de crianças acima do peso na África subiu de 4 milhões em 1990 para 13,5 milhões em 2011 . 0 problema atinge $8,5 \%$ da população com menos de cinco anos. Dieta ruim, sedentarismo e baixas taxas de amamentação são os principais motivos. 0 maior consumo de comida industrializada, com alto conteúdo de açúcar e gordura e baixo teor nutritivo, também contribui para a tendência (Organização Mundial de Saúde, 2012).

Dados inéditos da Organização Mundial de Saúde, obtidos com exclusividade pela BBC Brasil confirmam que, assim como o rápido crescimento do PIB (Produto Interno Bruto), o sobrepeso e a obesidade dispararam em países como China, Índia, África do Sul, Brasil e México. A China lidera lista dos obesos em crianças (Organização Mundial de Saúde, 2012).

A causa da obesidade é multifatorial e podem contribuir fatores genéticos, psicológicos, dietéticos, endócrinos e socioeconômicos, entre outros. Sabe-se que quando o pai e a mãe são obesos, o risco de a criança ser obesa é de $80 \%$. Se um dos genitores é obeso esta possibilidade é de $50 \%$ e se os pais são magros, a possibilidade é de $9 \%$. Estes índices são em parte explicados pela igualdade do padrão alimentar na família, não se podendo afirmar até que ponto estas tendências familiares são genéticas ou devidas ao meio ambiente (Bankoff, 2012, p. 18).

Nesse sentido, Bankoff et al. (2005), Bankoff e Bueno (2007), Bankoff et al. (2008), Zamai e Bankoff (2009) Rossi et al. (2010) comentam que estão acontecendo mudanças consideráveis em relação aos hábitos posturais, de alimentação e do estilo de vida das pessoas, pois estas gastam várias horas em atividades passivas como assistir TV, vídeo, computador, atividades admi- 
nistrativas nos escritórios, consultórios e outras, além da locomoção nos grandes centros, que traduz em gastos energéticos mínimos, contrapondo com a ingestão alimentar diária.

Bankoff, (2012), Freitas, Coelho \& Ribeiro, (2009) comentam que em relação aos hábitos de vida dos escolares foi verificado que $74 \%$ dos escolares, as famílias não possuem o hábito de tomar café da manhã em casa e eles se alimentam nas escolas. Quanto ao consumo destes escolares: $35,8 \%$ consomem biscoitos doces e $38,2 \%$ salgados e $52 \%$ consomem refrigerantes nas cantinas das escolas 5 dias por semana para ambos os sexos. Estes dados também contribuem para com o aumento de obesidade entre os escolares.

Quanto aos conteúdos da Educação Física Escolar no Brasil, se pauta a partir dos conhecimentos adquiridos nos cursos superiores de licenciatura em Educação Física. Conhecimentos estes, que permitem que o professor de educação física escolar possa trabalhar com esportes, danças, ginásticas, lutas, atletismo, brincadeiras, jogos, práticas corporais, avaliações físicas, educação e saúde e outras. A Educação Física Escolar enquanto disciplina ministrada da 5 a a 9a série do ensino fundamental e do $1^{\circ}$ ao $3^{\circ}$ colegial (ensino médio) deve também se ocupar da Responsabilidade Social dentro da escola na área de saúde (Bankoff, 2012).

O ensino sobre Saúde tem sido um desafio para a Educação Física Escolar no que se refere à possibilidade de garantir uma aprendizagem efetiva e transformadora de atitudes e hábitos de vida dos escolares. As experiências mostram que transmitir informações a respeito do funcionamento do corpo e das características das doenças, bem como de um elenco de hábitos de higiene, não é suficiente para que os alunos desenvolvam atitudes de vida saudável. A criança quando inicia sua vida escolar, ela traz consigo os valores de comportamentos favoráveis ou desfavoráveis à saúde oriundos da família e outros grupos de relação mais direta. Durante a infância e a adolescência, épocas decisivas na construção de condutas, a escola passa a assumir papel destacado devido à sua função social e por sua potencialidade para o desenvolvimento de um trabalho sistematizado e contínuo. Neste sentido, a educação física escolar poderia ser mais eficaz no sentido de promover conscientização e atividades físicas visando à manutenção da saúde e perda e peso (Bankoff, 2012).

No Brasil, a inatividade física, considerada nos momentos de lazer, é mais prevalente entre mulheres, idosos e indivíduos de baixo nível sócio-econômico (Ministério da Saúde, 2002, Monteiro et al. 2003), porém pesquisas de base populacional regionais ainda são escassas em nosso país (Matsudo et al, 2002, Baretta et al. 2007).

A Pesquisa de Orçamento Familiar (POF) divulgada pelo Instituto Brasileiro de Geografia e Estatística (IBGE) mostra que em todas as regiões do país, em todas as faixas etárias e em todas as faixas de renda aumentou contínua e substancialmente o percentual de pessoas com excesso de peso e obesas. 0 sobrepeso atinge mais de $30 \%$ das crianças entre 5 e 9 anos de idade, cerca de $20 \%$ da população entre 10 e 19 anos e nada menos que $48 \%$ das mulheres e $50,1 \%$ dos homens acima de 20 anos. Entre os $20 \%$ mais ricos, o excesso de peso chega a $61,8 \%$ na população de mais de 20 anos. Também nesse grupo concentra-se o maior percentual de obesos: 16,9\% (Ministério da Saúde, 2010, Jesus et al. 2010).

Além de se constituir em problema pelos riscos decorrentes do sobrepeso em si - como doenças do coração e diabetes - o sobrepeso é causado por uma alimentação pouco saudável. Para agravar o quadro, a prática regular de exercícios físicos está longe de fazer parte dos hábitos do brasileiro. Pesquisa de 2008 mostrou que apenas $10,2 \%$ da população com 14 anos ou mais têm alguma atividade física regular (Ministério da Saúde, 2010, Simon, Souza \& Souza, 2009).

Segundo o Manual de Saúde nas Américas-OMS e OPAS (2012), o elevado consumo de alimentos processados de alta densidade calórica, ricos em gorduras, açúcares e sal, associado com a diminuição significativa na ingestão de frutas e verduras, e uma redução da atividade física, provocou uma alarmante epidemia de sobrepeso e obesidade. Estima-se que na América Latina entre $50 \%$ e $60 \%$ dos adultos, e entre $7 \%$ e $12 \%$ das crianças menores de cinco anos - mais um terço dos adolescentes - tem sobrepeso ou são obesos. Mais ainda, prevê-se que essa cifra aumentará rapidamente e atingirá os 289 milhões em 2015 (39\% da população total). Em quase todos os países, o problema é mais marcante nas mulheres. Uma analise de 57 estudos prospectivos aponta para cada $5 \mathrm{~kg} / \mathrm{m} 2$ do índice de massa corporal (IMC) em excesso associa-se a um aumento próximo a $30 \%$ de mortalidade $40 \%$ por AVC, $60 \%-120 \%$ por complicações associadas ao diabetes, $10 \%$ por câncer e $20 \%$ por doenças respiratórias crônicas).

\section{OBJETIVO GERAL}

Estudar como a Educação Física Escolar tem tratado o tema obesidade. 


\section{OBJETIVOS ESPECÍFICOS}

a. Verificar como a educação Física Escolar tem trabalhado sobre o tema obesidade nas escolas;

b. Como os alunos encaram as aulas de Educação Física em suas escolas (o que aprendem, qual a importância desta disciplina na vida deles, em que sentido ela pode mudar o comportamento dos mesmos em relação à uma alimentação adequada, uma atividade física regular, dentre outros fatores);

c. Como os professores de Educação Física estão atuando diante deste problema (como trabalham como encaram como é o trato com os alunos com distúrbio de obesidade dentro da escola);

d. Como a Educação Física Escolar poderia ser mais eficaz no sentido de promover uma conscientização dos alunos no que diz respeito à manutenção da saúde e à perda de peso.

\section{METODOLOGIA}

\section{População estudada}

Dentre as escolas escolhidas num primeiro momento, foram selecionadas duas: uma Estadual, de nível socioeconômico médio-baixo, e outra particular, de nível socioeconômico alto. Nas escolas, foi selecionada uma classe de cada série $\left(5^{\underline{a}}, 6^{a}, 7^{a}\right.$ e $8^{a}$ ), que é o universo que este estudo tem como base. A escolha das escolas foi feita aleatoriamente, a partir da permissão das mesmas. Foram desenvolvidos dois protocolos: um voltado para os alunos de $5^{\mathrm{a}}$ à $8^{\underline{a}}$ séries do Ensino Fundamental, outro para os professores de Educação Física Escolar.

0 protocolo dirigido aos alunos foi formulado com perguntas sobre o modo como é desenvolvida a aula de Educação Física na escola; o nível de participação do aluno nas aulas; os temas relacionados à saúde tratados nas aulas; e a prática de alguma atividade física regular. 0 protocolo voltado para os professores aborda questões também sobre a presença do tema obesidade e saúde na escola, nutrição, fisiologia, atividade física e o modo como é desenvolvido o trabalho com este grupo (os alunos com distúrbio de obesidade).

0 trabalho foi desenvolvido em duas escolas da cidade de Campinas, sendo uma da rede Estadual, de nível sócio-econômico médio-baixo, e outra particular, de nível sócio-econômico alto. Foi verificada a possi- bilidade de se aplicar os questionários, e para isso, foram consultados os professores de educação Física e os diretores das escolas, a fim de que o trabalho transcorresse da melhor maneira possível. Através de solicitações das escolas, o nome das mesmas não aparecerá nesta pesquisa, por não ser relevante seu conhecimento.

\section{Delimitação do problema}

Sabendo-se que os conteúdos programáticos das aulas de Educação Física na maioria das escolas, são compostos por esportes e, geralmente voltados para competições, pergunta-se: qual a importância do aluno, enquanto ser humano, dentro da escola e, mais especificamente, dentro da Educação Física?

É notório que os alunos, dentro de uma mesma aula, possuem objetivos e interesses diferentes, e que é quase impossível agradar a todos, atender a todos de uma maneira uniforme.

Isto ocorre em todas as disciplinas. Mas também não é o caso de se ignorar o problema do distúrbio de obesidade (bem como outros problemas de saúde) só pelo fato de que pode ser que não seja a maioria das pessoas que sofrem deste problema.

É preciso conscientizar os alunos sobre o modo mais adequado de se alimentar, se exercitar e de viver a vida com prazer. E qual é o melhor local para se começar a aprender tudo isso senão a escola?

\section{RESULTADOS}

Analisar os gráficos obtidos a partir dos protocolos que foram passados para professores de Educação Física e alunos do Ensino Fundamental (de 5a à 8aa séries).

Primeiramente, analisaremos os gráficos obtidos a partir dos protocolos para os alunos. Em seguida analisaremos os dados obtidos a partir do protocolo para os professores de Educação Física. Ambos os protocolos foram aplicados nas escolas a partir da permissão das mesmas. Apenas um professor de Educação Física não respondeu ao protocolo.

\section{Análise dos Gráficos - Escola da Rede Estadual e Escola Particular}

Antes de iniciar a análise dos gráficos, é preciso esclarecer que, no questionário, foi permitido aos alunos escolherem e responderem mais de uma questão. 
Gráfico 1. Participação nas aulas de Educação Física Escolar (quantas vezes por semana)

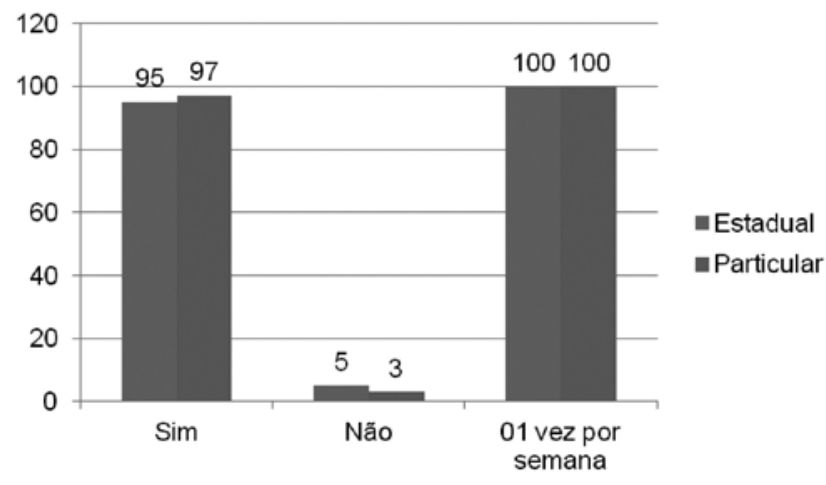

Este gráfico mostra a participação dos alunos nas aulas de Educação Física escolar quanto à freqüência. $\mathrm{Na}$ escola estadual, 95\% dos alunos fazem as aulas de Educação Física, enquanto que na escola particular, 97\% . Em ambas as escolas, as aulas de Educação Física são realizadas uma vez por semana, sendo aula dupla, com uma hora e meia de duração.

Gráfico 2. Nível de participação nas aulas de Educação Física.

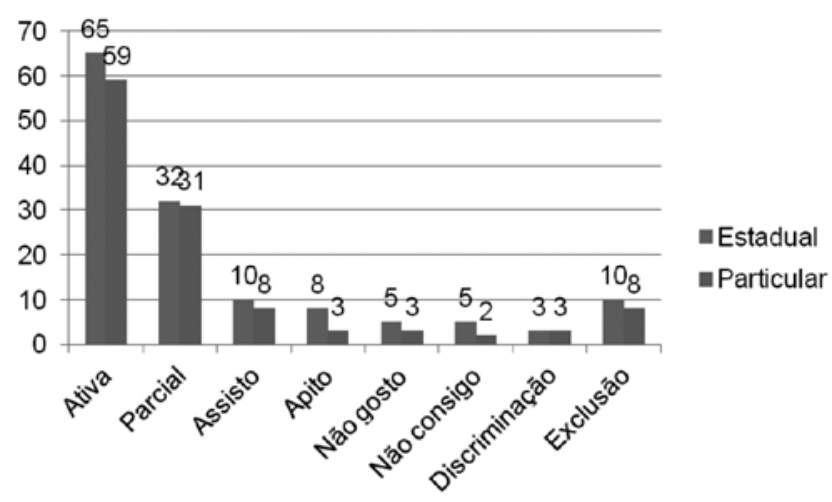

No gráfico 2, é mostrado o nível de participação dos alunos nas aulas de Educação Física em ambas as escolas em relação: se é ativa durante a aula toda; se é parcialmente ativo; se o aluno apenas assiste; se ele apita os jogos ou fica no gol, se o aluno não gosta das aulas; se o aluno não consegue realizar o que é proposto pelo professor; se ele é discriminado; e se ele se sente excluído. Em ambas as escolas, a maioria dos alunos participa ativamente das aulas, seguido pela participação parcial, que seria o aluno que não faz a aula toda. Dos alunos que responderam que não conseguem realizar as tarefas que o professor pede os quais se sentem discriminados ou excluídos, os motivos foram: reumatismo, hérnia de disco, os amigos "zoam" e um não respondeu. A minoria dos alunos em ambas as escolas não fazem Educação Física porque os amigos discriminam (3\%).
Gráfico 3. Abordagem de temas sobre saúde nas aulas de Educação Física.

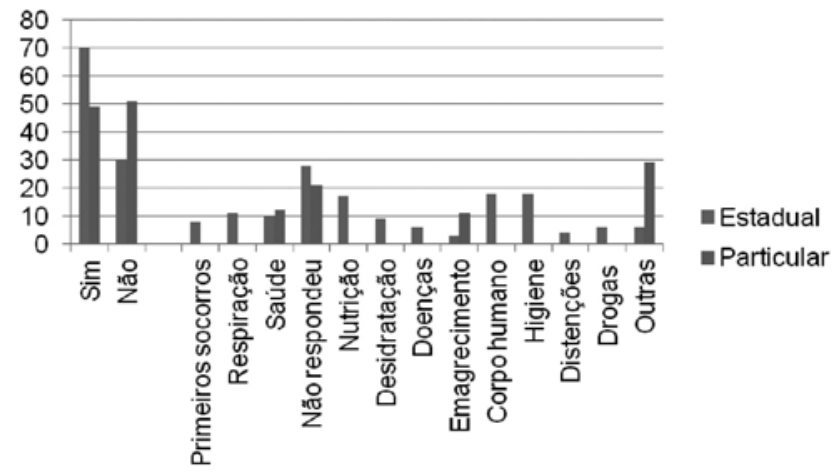

Sobre a abordagem de temas sobre saúde nas aulas de Educação Física, 70\% dos alunos da escola estadual responderam terem tido este tema; já na escola particular, apenas 49\% disseram ter tido este tema. Dos temas abordados, na escola estadual e particular, respectivamente, estão: saúde (10\% e $12 \%)$, emagrecimento $(3 \%, 11 \%)$ e outros temas $(6 \%, 29 \%)$, não respondeu $(28 \%, 21 \%)$. Quanto aos temas primeiro socorros (8\%), respiração (11\%), nutrição (17\%), desidratação (9\%), doenças (ex: dengue, AIDS, alergias) (6\%), corpo humano (18\%), distensões (4\%), drogas (6\%) e higiene $(18 \%)$ apenas foram abordados pela Escola Estadual conforme gráfico.

Gráfico 4. Se o Professor nas aulas de educação física enfatiza a importância da pratica da atividade física regular.

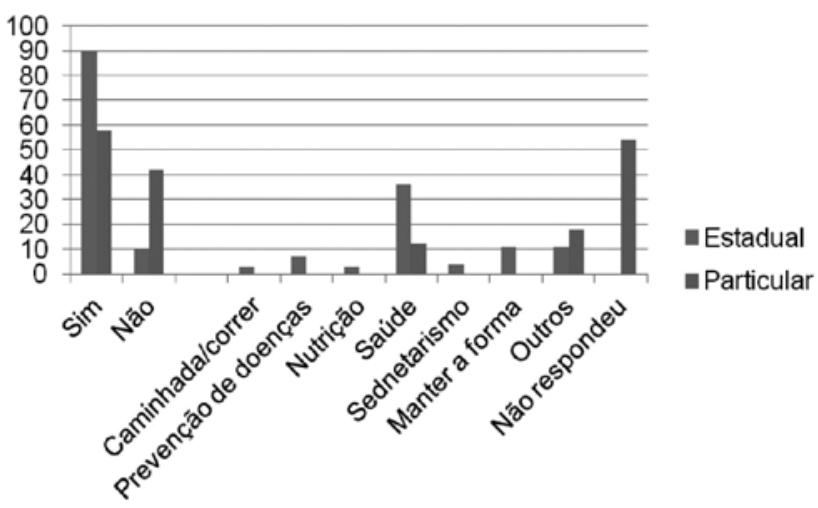

Quanto à pergunta aos alunos se o professor enfatiza nas aulas de educação física a importância da prática da atividade física regular, $90 \%$ dos alunos da escola estadual responderam que sim, o professor aborda a importância, contra $58 \%$ da escola particular. Na escola estadual, os temas mais abordados foram: Caminhadas/corridas $3 \%$, prevenção de doenças $7 \%$, nutrição $3 \%$, saúde $36 \%$, sedentarismo $4 \%$, manter a forma $11 \%$, outros (articulações, crescimento, aquecimento, resistência, alon- 
gamento) $11 \%$. Já na escola particular, os temas mais abordados foram: saúde $12 \%$, outros (testes físicos, condicionamento, melhora do desempenho, trabalhos em grupo) $18 \%$ e $54 \%$ dos alunos não responderam.

Gráfico 5. Se o aluno pratica alguma atividade física fora da escola.

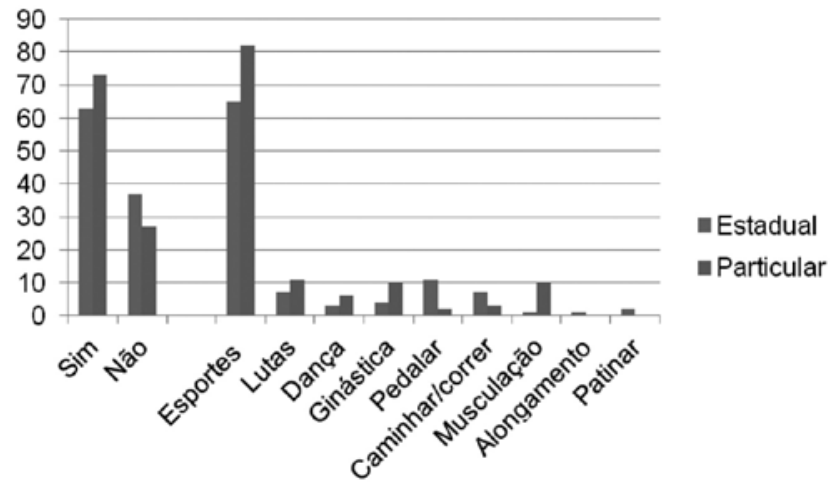

Este gráfico mostra que 63\% dos alunos da escola estadual praticam alguma atividade física fora da escola, enquanto que $73 \%$ da escola particular praticam. Dentre as atividades praticadas na escola estadual e na particular, respectivamente, estão: esportes $(65 \%, 82 \%)$, lutas $(7 \%, 11 \%)$, dança $(3 \%, 6 \%)$, ginástica $(4 \%, 10 \%)$, pedalar (11\%,2\%), caminhar/correr $(7 \%, 3 \%)$, musculação $(1 \%$, $10 \%)$, alongamento $(1 \%, 0 \%)$, patinação $(2 \%, 0 \%)$ e $1 \%$ dos alunos da escola estadual não responderam. Vale ressaltar aqui, mais uma vez, que foi permitido aos alunos a escolha de mais de uma resposta.

Gráfico 6. Abordagem do tema obesidade pelo professor de educação física.

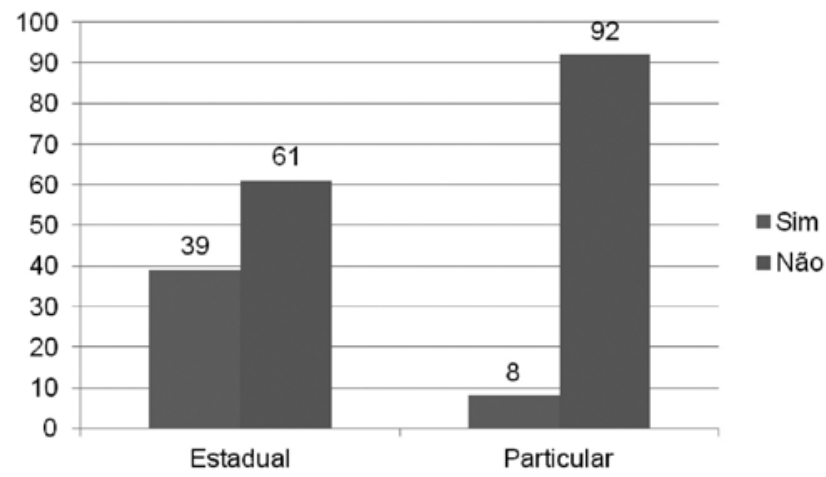

Quanto ao tema obesidade, 39\% dos alunos da escola estadual responderam que sim, o professor já abordou sobre o tema, enquanto que apenas $8 \%$ dos alunos da escola particular responderam que sim. Nesta questão, o que pode ter ocorrido é que os alunos tenham se esquecido se o professor abordou sobre o tema.
Gráfico 7. A escola oferece alguma atividade física extraclasse.

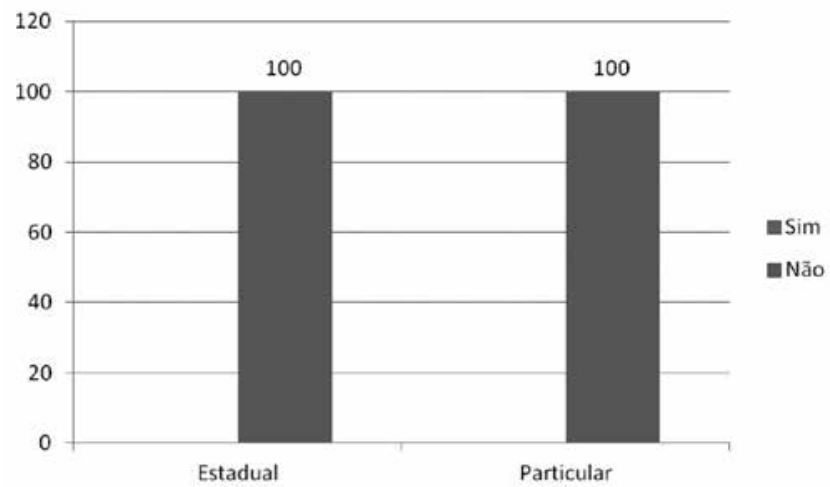

Ambas as escolas não oferecem nenhuma atividade física extraclasse, como por exemplo, time de futebol, time de basquete, dança e outras.

Gráfico 8. 0 aluno gosta do próprio corpo.

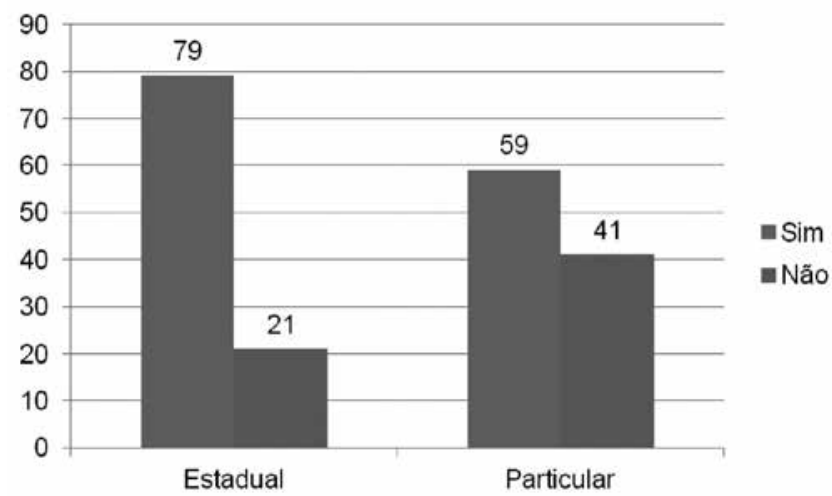

Ao serem perguntados sobre se gostam do corpo, 79\% dos alunos da escola estadual responderam que sim, enquanto que $59 \%$ dos alunos da escola particular responderam que sim.

\section{Gráfico 9. Desejo de mudança de alguma(s) parte(s) do corpo.}

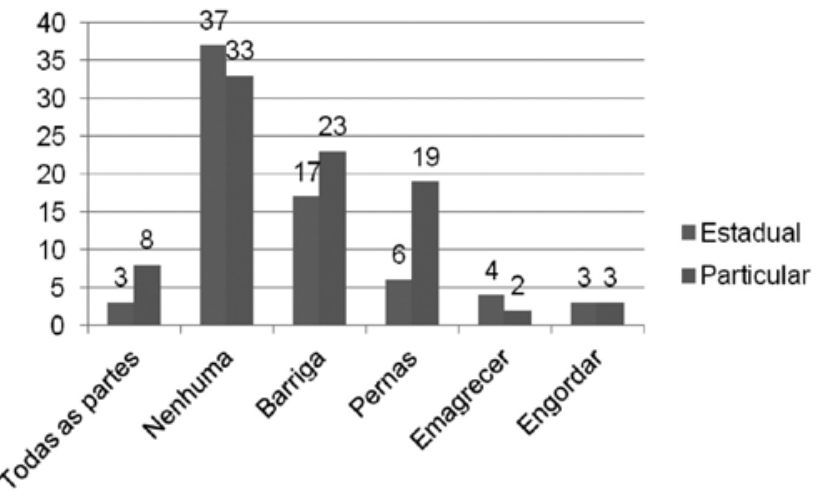


No gráfico 9 está expresso o desejo de mudança corporal (ou não) por parte dos alunos. Analisando a escola estadual e particular, respectivamente: todas as partes do corpo $(3 \%, 8 \%)$, nenhuma parte $(37 \%, 33 \%)$, barriga $(17 \%, 23 \%)$, pernas $(6 \%, 19 \%)$, emagrecer $(4 \%, 2 \%)$, e engordar $(3 \%, 3 \%)$.

\section{Gráfico 10. Conhecimento sobre seu peso corporal.}

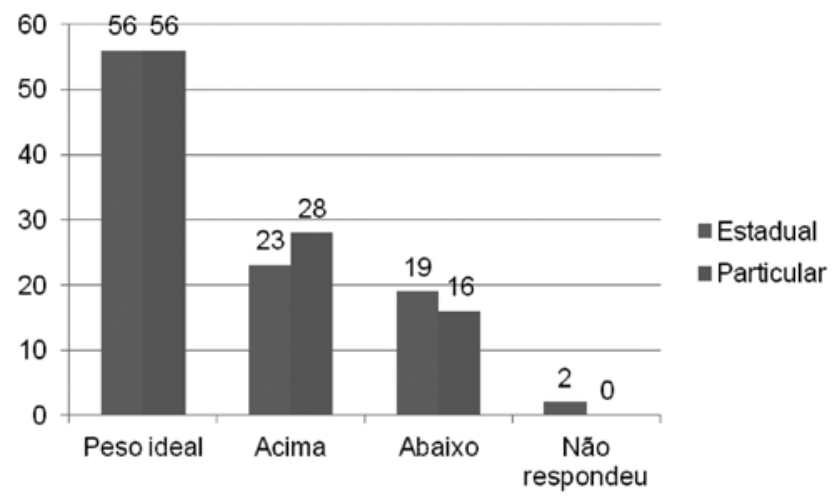

Foi perguntado aos alunos se eles achavam que estavam na sua faixa de peso ideal, ou acima ou abaixo. $\mathrm{Na}$ escola estadual, $56 \%$ dos alunos responderam que estavam dentro da faixa de peso ideal; $23 \%$ responderam que estavam acima da faixa de peso ideal; $19 \%$ responderam que estavam abaixo da faixa de peso ideal; e $2 \%$ não responderam à questão. Na escola particular, $56 \%$ dos alunos responderam que estavam dentro da faixa de peso ideal; $28 \%$ responderam que estavam acima da faixa de peso ideal; e $16 \%$ responderam que estavam abaixo da faixa de peso ideal.

\section{TRANSCRIÇÃO E ANÁLISE DOS PROTOCOLOS DOS PROFESSORES}

As duas escolas compunham o total de 03 professores, sendo que um deles não respondeu o questionário, então, ficamos apenas com as respostas de 02 professores, ou seja, 01 da escola estadual e outro da escola particular. Denominamos de Professor 1(escola estadual) e Professor 2 (escola particular.

\section{Professor 1-Escola Estadual}

O professor da escola estadual está formado há 20 anos e ministra aulas há 17 anos e se formou na Universidade Castelo Branco-RJ. Ele respondeu que sempre aborda temas sobre saúde sobre alimentação saudável e adequada, higiene e o porquê das atividades que estão realizando. Também, respondeu que fala sobre nutrição e os benefícios das atividades físicas para que os alunos tenham melhor compreensão sobre seu físico. Relatou que em seu planejamento contempla atividades físicas aeróbias e anaeróbias, bem como, alongamentos, relaxamentos e sobre lesões. Quanto ao tema obesidade está presente na maioria das aulas em forma de discussão com os alunos e também promove atividades físicas com objetivos de perdas de peso corporal, aumento da massa muscular e melhora das capacidades cardiorrespiratória entre outros temas. Relatou que em suas turmas não possui alunos com obesidade.

\section{Professor 2: Escola Particular}

0 professor da escola particular está formado há 10 anos e ministra aulas há 10 anos e se formou na Universidade Estadual de Campinas-Campinas -SP. Ele respondeu que aborda temas sobre saúde de uma forma genérica, porém, enfatiza sobre a importância da atividade física e escreveu que o objetivo principal é a sociabilização e que para isso ele utiliza muitos jogos e quando vai para a sala de aula em dias chuvosos procura discutir temas como: relacionamento entre colegas, desentendimento e brigas e outros.Ele acha importante que os alunos tenham conhecimentos sobre nutrição, obesidade e os benefícios das atividades físicas, porém, não consegue prender atenção dos alunos para falar sobre estes temas e relatou que não consegue ministrar aos alunos. Disse que quando preparou uma aula teórica aos alunos sobre estes temas a experiência foi decepcionante e daí, voltou com alunos na quadra. Respondeu que não possui em seu planejamento temas sobre saúde e não explica aos alunos se são atividades aeróbias ou anaeróbias, e também, não promove atividades que contribuam com perda de peso e nem realiza atividades para melhora das capacidades cardiorrespiratória Escreveu que possui alunos obesos e acima do peso. Foi perguntado como ele trabalha com os alunos obesos. Ele escreveu que estes alunos não topam praticar esporte e automaticamente eles ficam a parte do grupo, e escreveu que a atitude dele (professor) é não forçar este aluno a praticar atividades, mas ir conversando com o aluno paralelamente longe dos outros alunos e aos poucos ele participa das atividades. Primeiro, espero ele sentir segurança e amizade e aí, aos poucos, vou falando diretamente sobre o problema da obesidade ( que há necessidade, caso ele queira, emagrecer), de muita força de vontade e às vezes, até acompanhamento médico".

\section{DISCUSSÃO}

Parece-nos que a educação física escolar em ambas as escolas possuem objetivos muito diferentes em relação a nossa temática de estudo "Como a Educação Física 
Escolar tem tratado o tema obesidade". Analisando os questionários dos professores, podemos perceber que eles tratam sobre alguns assuntos relacionados à saúde. Não ficou claro nas respostas como estes temas são abordados, se em aulas teóricas ou práticas. 0 professor da escola estadual contempla em seu planejamento temas relacionado as saúde, enquanto que o professor da escola particular não contempla em seu planejamento temas relacionados a saúde, relata que em dias chuvosos leva os alunos a sala de aula e discute comportamentos dos alunos.Quanto a obesidade, já teve contato com alunos obesos em suas aulas e disse que conversava com eles, para aos poucos, irem participando das atividades, falando também mais abertamente sobre o assunto. Disse ter dificuldade em ministrar aula teórica pela falta de atenção dos alunos e acabou desistindo de ministrar aulas teóricas.

Observamos os dados coletados e apresentados no gráfico 4 se o professor enfatiza em suas aulas sobre a importância da prática da atividade física regular: 90\% dos alunos da escola estadual responderam que sim, o professor aborda a importância, e 58\% da escola particular. Em relação às respostas, ficou evidente que na escola estadual o professor valoriza mais e dá maior importância sobre este tema. Na escola estadual, os temas mais abordados foram: Caminhadas/corridas 3\%, prevenção de doenças $7 \%$, nutrição $3 \%$, saúde $36 \%$, sedentarismo $4 \%$, manter a forma $11 \%$, outros (articulações, crescimento, aquecimento, resistência, alongamento) $11 \%$. Já na escola particular, os temas mais abordados foram: saúde $12 \%$, outros (testes físicos, condicionamento, melhora do desempenho, trabalhos em grupo) $18 \%$ e $54 \%$ dos alunos não responderam.

Bankoff, (2012), Guedes e Guedes (1997), Ministério da Saúde (2012) relatam que a educação física escolar possui conhecimentos da área de saúde e biologia advinda dos cursos de licenciatura em educação física que poderiam contribuir, e em seus planejamentos contemplar os referidos temas nas aulas de educação física, no sentido de melhor qualidade de vida dos alunos. Ainda Bankoff, (2012, p. 32) relata que as crianças quando chegam à escola trazem consigo os hábitos alimentares adquiridos na família os quais são somados aqueles dentro do ambiente escolar (consumo de salgados, refrigerantes, doces e outros) tornando-os com sobrepeso e mais obesos. Além da educação física há necessidade que outras disciplinas contemplem em seus planejamentos temas relacionados a saúde, especificamente hábitos alimentares, obesidade, nutrição, como fator de prevenção de doenças. Quanto ao tema obesidade se o professor já havia falado sobre o referido tema, os alunos da escola estadual responderam $38 \%$ e na particular $8 \%$. Estes resultados demonstram que nossos escolares possuem poucas informações sobre esta patologia, muito embora, o professor da escola particular relatou que já teve obesos em suas classes e tinha dificuldades de trabalhar com os mesmos. Em relação à satisfação corporal a maioria respondeu que estão satisfeitos com o corpo. 0 percentual foi maior na escola estadual.

\section{CONSIDERAÇÕES FINAIS}

Após a análise dos gráficos e dos protocolos dos professores, podemos pensar um pouco mais concretamente, como o tema obesidade tem sido tratado nas escolas. Os dados nos mostram que os professores abordam sobre o tema obesidade, bem como saúde, em suas aulas. Não dá para saber se a abordagem desses assuntos é feita em sala de aula (com aulas teóricas), ou na quadra, durante as atividades.

Quanto aos assuntos mais abordados em sala, analisando tanto protocolos de alunos quanto de professores, estão: nutrição, importância da atividade física, doenças, emagrecimento, corpo humano, higiene, distensões, drogas, respiração, desidratação e primeiros socorros. Segundo a maioria dos alunos, os professores abordam sobre a importância de uma atividade física regular, mas não abordam sobre o tema obesidade. Ambas as escolas pesquisadas não oferecem uma atividade física extraclasse, como escolinhas de algum esporte.

A maioria dos alunos participa ativamente das aulas, seguidos por aqueles que participam parcialmente, ou seja, não fazem a aula toda, ou faltam às aulas; a maioria também pratica algum tipo de atividade física fora da escola, muitas vezes praticando mais de um tipo. A maioria deles diz gostar de seus corpos e não querem mudar nenhuma parte.

Uma questão interessante, a questão 10, na qual foi perguntado aos alunos se eles achavam que estavam na faixa de peso ideal, a maioria respondeu que sim. Mas a maioria deles não sabia informar com exatidão sobre sua altura e peso perguntados no início do protocolo. E não foi analisado nenhum tipo de arquivo onde poderia ser encontrada alguma informação sobre esses dados.

Penso que a Educação Física Escolar tem como um de seus objetivos os de ensinar as noções básicas sobre atividade física, saúde, nutrição e prevenção de doenças. 
Como o professor tem que estar comprometido com a verdade e ensiná-la aos seus alunos, nós, professores de Educação Física têm que estar comprometidos com a nossa verdade, que não se restringe somente aos conteúdos esporte, lutas, dança, ginástica e jogos; mas que também trata sobre o funcionamento do corpo, não como uma máquina estática, programável, mas como um corpo que sente, que cansa, que tem sede, entre outras coisas. Um corpo que tem necessidades. Um corpo que precisa de atenção.

Acredito que os conteúdos básicos de fisiologia, nutrição e saúde sejam essenciais para que nossos alunos possam sair da escola com conhecimento sobre Educação Física e para que ela sirva; bem como o conhecimento do seu próprio corpo. Assim como o aprendizado das outras matérias pode permitir que ele compreenda o "mundo lá fora", ou o mundo da matemática, permitindo que ele seja capaz de fazer os cálculos básicos para utilizar na sua vida cotidiana, assim deve ser o aprendizado da Educação Física: que dê autonomia para nossos alunos; que permitam escolher uma atividade física regular que mais lhes agrade, sabendo de seus efeitos e benefícios, e sabendo que ela pode prevenir o surgimento de diversas doenças; que saibam a importância de uma alimentação adequada, e que coloquem esse aprendizado em prática no seu dia-a-dia, e caso queiram emagrecer ou engordar, tenham bases fundamentadas e saibam como atingir seus objetivos; que possam praticar seu lazer de forma mais efetiva... enfim, que possam desfrutar da atividade física conscientemente.

\section{REFERENCIAS BIBLIOGRÁFICAS}

Bankoff, A. D. P. , Scarpa, E.M. , Zamai, C. A., Moraes, A. C.(2002). Study of the intensity of Effort During a Program of Physical Activities in Obese Adolescents. In: 7th Congress of the European College of Sports Science (p. 899-899) Atenas.

Bankoff, A. D. P. (2005). Programa Mexa-se: Responsabilidade Social. In: 5o Congresso Brasileiro de Atividade Física e Saúde (p. 174-176) Florianópolis.

Bankoff, A.D.P, Bueno, E. (2007). Programa de Convivência e atividade Física na Unicamp: relato de experiência. In: VII Fórum de Educação Física dos Países do MERCOSUL (p.15-17) Foz do Iguaçu.

Bankoff, A.D.B. et al. (2008). Implantação do programa de convivência e atividade física na Unicamp Mexa-se. Anais... II Simpósio de Profissionais da Unicamp -II Simtec (p. 18-21) Campinas.
Bankoff, A. D. P. (2012). Doenças Crônicas Não Transmissíveis em Crianças e Adolescentes. In Carlos A. Zamai e Alan A. Rodrigues. (Org.). Saúde Escolar: A Responsabilidade de Ensinar. Jundiaí: Paco Editorial.

Baretta, e Baretta, M., Peres, K. G. (2007). Nível de atividade física e fatores associados em adultos no Município de Joaçaba, Santa Catarina, Cad. Saúde Pública, Rio de Janeiro, 23 (7) 1595-1602.

Freitas, A. S.S, Coelho, S.C, Ribeiro, L. R. (2009). Obesidade infantil: influência de hábitos alimentares inadequados. Saúde \& Amb Ver, 4, (2) 9-16.

Guedes, D. P., Guedes, J. E.R.P. (1997). Crescimento, composição corporal e desempenho motor de crianças e adolescentes: São Paulo: CLR Balieiro.

Jesus, G.M, et al.(2010) Fatores determinantes do sobrepeso em crianças menores de quatro anos de idade. J de Pedriatr, 86, (4) 311-316.

Mello, E. D., Luft, V. C., Meyer, F. (2004). Obesidade infantil: como podemos ser eficazes? J de Pediatr, 80, (3) 173-82.

Ministério da Saúde. (2012). Secretaria de Vigilância em Saúde e Secretaria de Gestão

Estratégica e Participativa. Vigitel Brasil 2011: vigilância de fatores de risco e proteção para doenças crônicas por inquérito telefônico. Brasília.

Oorganização Mundial de Saúde- (2013). Desigualdades na área da saúde persistem no Brasil.Setembro de 2012. Recuperado de http://www.onu.org.br/ desigualdades-na-area-da-saude-persistem-no-brasil-aponta-organizacao-mundial-da-saude/

Pollock, M. L., Wilmore, J. H. (1993). Exercício na saúde e na doença. Rio de Janeiro: Editora MEDSI.

Rinaldi, A. E. M et al. (2008). Contribuições das práticas alimentares e inatividade física para o excesso de peso infantil. Rev Paul Pediatr, 26, (3) 271-277.

Rossi, C.E et al. (2010). Influência da televisão no consumo alimentar e na obesidade em crianças e adolescentes: uma revisão sistemática. Rev Nutr, 23,(4) 607-620.

Simon, V.G.N., Souza, J. M. P., Souza, S.B. (2009) Aleitamento materno, alimentação complementar, sobrepeso e a obesidade em pré-escolares. Rev Saúde Pública, 43, (1), 60-69. 
Siqueira, P.P., Alves, J.G.B., Figueira, J.N. (2009). Fatores associados ao excesso de peso em crianças de uma favela do Nordeste brasileiro. Rev Paul Pediatr, 27, (3), 251- 257.
Zamai, C.A., Bankoff, A.D.P. (2009). Impacto das atividades físicas nos indicadores de saúde de sujeitos adultos: programa mexa-se. Anais III Congresso de Ciências do Desporto (p.78-79) Campinas. 